\title{
Induction of the differentiation of cultured endometrial carcinoma cells by type I collagen: Relevance of sulfolipids
}

\author{
MIKIO MIKAMI $^{1}$, MAKIKO HARASAWA ${ }^{1}$, TARO SUGIYAMA ${ }^{1}$, YOSHIHIRO NISHIJIMA ${ }^{1}$, \\ YUMIKO GOTO $^{1}$, TAKESHI HIRASAWA ${ }^{1}$, TOSHINARI MURAMATSU ${ }^{1}$ and MASAO IWAMORI ${ }^{2}$ \\ ${ }^{1}$ Department of Obstetrics and Gynecology, Tokai University School of Medicine, Kanagawa; \\ ${ }^{2}$ Department of Biochemistry, Faculty of Science and Technology, Kinki University, Osaka 577-8502, Japan
}

Received February 9, 2009; Accepted June 9, 2009

DOI: 10.3892/ol_00000021

\begin{abstract}
This study aimed to promote gland formation in cells derived from endometrial cancer, and assess the relevance of sulfolipids by performing culture with type I collagen. Tumors were developed in nude mice using cultured cell lines, gland formation was induced by culture with type I collagen and the composition of tumor cell sulfolipids was analyzed. Results showed that after culturing the cells on type I collagen gel, the gel was floated. Another layer of gel was placed on top so that the cells were sandwiched between two layers. Using this method, it was possible to induce gland formation in cells that formed only poorly differentiated tumors in nude mice. Mucous staining and electron microscopy demonstrated polarity of the glands. The cell lines that showed gland formation expressed sulfolipids, but not cholesterol sulfate. In conclusion, type I collagen and sulfolipids are involved in the process of gland formation in endometrioid adenocarcinoma.
\end{abstract}

\section{Introduction}

It has been reported that there is a relationship between the prognosis of endometrial carcinoma and the extent of tumor differentiation. Poorly differentiated adenocarcinoma shows a faster progression and is more refractory to therapy than well-differentiated adenocarcinoma, resulting in poor prognosis. However, little research has been conducted on the process of differentiation of endometrial cancer. Research on endometrial cancer usually employs tumor cell lines. When established, such cell lines possess the characteristics of the original tumor, but due to an increasing number of passages the original morphological and functional features are gradually lost. For example, a cell line derived from well-differentiated

Correspondence to: Dr Mikio Mikami, Department of Obstetrics and Gynecology, Tokai University School of Medicine, Shimokasuya, Isehara, Kanagawa 259-11, Japan

E-mail:mmikami@is.icc.u-tokai.ac.jp

Key words: uterine neoplasm, endometrioid adenocarcinoma, grading, differentiation, glandular differentiation, sulfolipids endometrial cancer that forms glands in transplanted tumors shortly after establishment may be transformed to poorly differentiated cancer without any gland formation after $\geq 50$ passages.

A number of reports on the role of the extracellular matrix $(\mathrm{ECM})$ in the proliferation, differentiation, metastasis and infiltration of cancer are available. It has been reported that the differentiation of endometrial carcinoma and gland formation can be achieved by culturing tumor cells in or on ECM (Matrigel ${ }^{\mathrm{TM}}$ ) produced by Engelbreth-Holm-Swam mouse sarcoma (1). However, Matrigel is ECM produced by a tumor, and has an unknown composition; thus, it remains unclear which of its components are involved in gland formation.

Our studies of human endometrial tissue have demonstrated that sulfolipids are expressed during the secretory rather than the proliferative phase, i.e., sulfolipid expression, which is controlled by estrogen, is reduced during the proliferative phase (2). We also analyzed the composition of sulfolipids expressed in cultured gynecological cell lines such as those derived from cervical, ovarian or endometrial cancer, and showed that sulfolipids are particularly expressed in cell lines originating from endometrial cancer $(3,4)$. Results suggest that sulfolipids are involved in the development of cancer as well as in the differentiation of the endometrium.

The objective of the present study was to induce the differentiation of poorly differentiated endometrial cancer into well-differentiated cancer. Cell lines derived from endometrial cancer that showed a poorly differentiated morphology after transplantation into nude mice were cultured with type I collagen to induce morphological differentiation (i.e., gland formation). Consequently, the role of sulfolipids in the induction of differentiation was investigated.

\section{Materials and methods}

Cell lines and culture. The six cell lines shown in Table I were provided courtesy of the sources mentioned. Cells were cultured in Ham's F-12 medium containing $10 \%$ fetal calf serum and antibiotics (100 U/ml penicillin and $100 \mathrm{mg} / \mathrm{ml}$ streptomycin) at $37^{\circ} \mathrm{C}$ in an atmosphere of $5 \% \mathrm{CO}_{2}$, and $100 \%$ humidity. The cells were then detached with $0.05 \%$ EDTAtrypsin for passaging. The number of passages for each cell line used in these experiments is shown in Table I. 
Table I. Characteristics of endometrial adenocarcinoma cell lines used in this experiment.

\begin{tabular}{lccc}
\hline Cell line & Refs. & Passage no. & $\begin{array}{c}\text { Histology of } \\
\text { the original tumor }\end{array}$ \\
\hline SNG-II & $(5)$ & $>100$ & G1 \\
SNG-M & $(6)$ & $>100$ & G2 \\
Ishikawa & $(7)$ & $>100$ & G1 \\
HEC108 & $(8)$ & $>100$ & G3 \\
HHUA & $(9)$ & $>100$ & G1 \\
HOOUA & $(10)$ & $>100$ & Undifferentiated \\
\hline
\end{tabular}

G1, well-differentiated; G2, moderately differentiated and G3, poorly differentiated adenocarcinoma.

Tumor transplantation into nude mice. Female BALB/c nude mice were used at 6-8 weeks of age. Tumor cells $\left(1 \times 10^{7}\right)$ were injected subcutaneously into the back of each mouse. After a mass measuring $\sim 2 \mathrm{~cm}$ formed, each animal was sacrificed and the tumor was resected immediately.

Floating collagen gel culture. After $1 \mathrm{ml}$ of type I collagen gel (Cellmatrix I-A, Nitta Gelatin Inc., Japan) was placed into a $35-\mathrm{mm}$ dish, $2 \times 10^{6}$ tumor cells were cultured on it for 2 days. The gel was then detached from the dish, allowed to float in the medium and culture was continued for 28 days. When sufficient cells had developed, another layer of collagen gel was placed on top, and culture was continued for 3 more days with the cells sandwiched between the gel layers. This floating sandwich culture using two layers of type I collagen gel was performed in Ham's F-12 medium containing $10 \%$ fetal calf serum and antibiotics (100 U/ml penicillin and $100 \mathrm{mg} / \mathrm{ml}$ streptomycin) at $37^{\circ} \mathrm{C}$ in an atmosphere of $5 \% \mathrm{CO}_{2}$ and $100 \%$ humidity. The medium was changed every other day.

Light and electron microscopy. Following completion of the culture, the tumor cell colonies were fixed with $10 \%$ neutral formalin, embedded in paraffin and cut into sections perpendicular to the gel surface. Then the sections were stained with hematoxylin and eosin (H\&E) and alcian blue for light microscopy. Tumors grown in nude mice were also stained using the same methods. Other tumor specimens were fixed by the addition of $4 \%$ sucrose $/ 60 \mathrm{mM}$ cacodylate buffer $(\mathrm{pH} 7.4)$ containing $4 \%$ paraformaldehyde and 5\% glutaraldehyde to the medium in equal proportions, followed by post fixation with $1 \%$ osmium tetroxide, dehydration and embedding in Epon 812. Ultrathin sections were cut perpendicular to the surface of the culture dish, double-stained with uranyl and lead acetate, and observed under a transmission electron microscope (Hitachi H-7000).

Analysis of sulfolipids. Cell lines derived from the endometrial cancers listed in Table I were cultured for $72 \mathrm{~h}$ in Ham's F-12 medium containing 10\% fetal calf serum and antibiotics (100 U/ml penicillin and $100 \mathrm{mg} / \mathrm{ml}$ streptomycin). ${ }^{35} \mathrm{~S}$-labelled $\mathrm{Na}_{2} \mathrm{SO}_{4}$ (ICN Biomedicals, USA) was added at $20 \mu \mathrm{Ci} / \mathrm{ml}$.
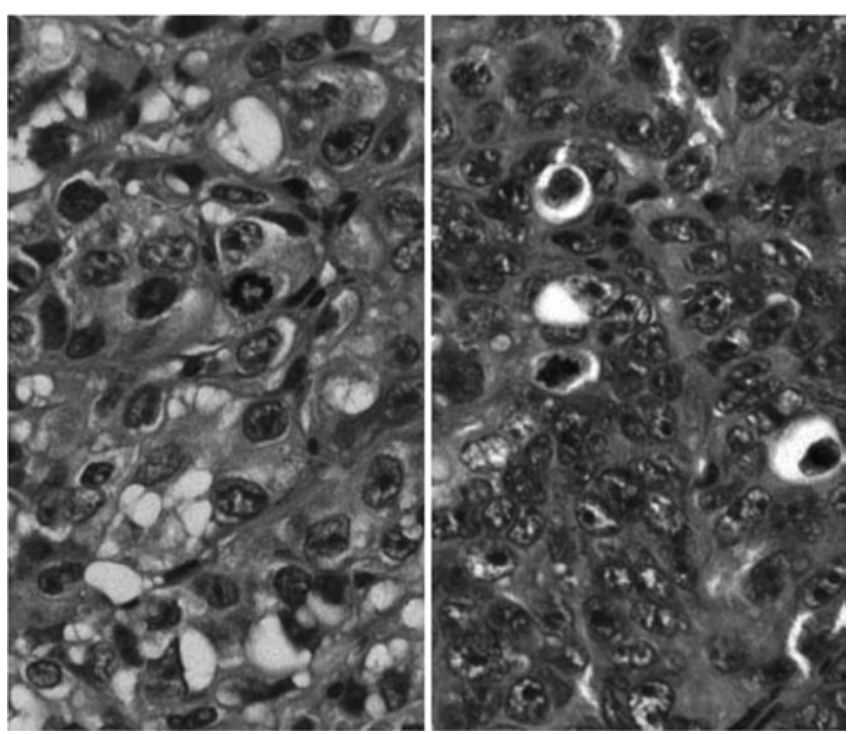

Figure 1. Hematoxylin and eosin-stained specimens of the tumors formed in nude mice by the transplanted SNG-M (left panel) and HHUA cell (right panel) lines. The tumors that grew in mice injected with the cells were solid and did not show any gland formation or other signs of differentiation.
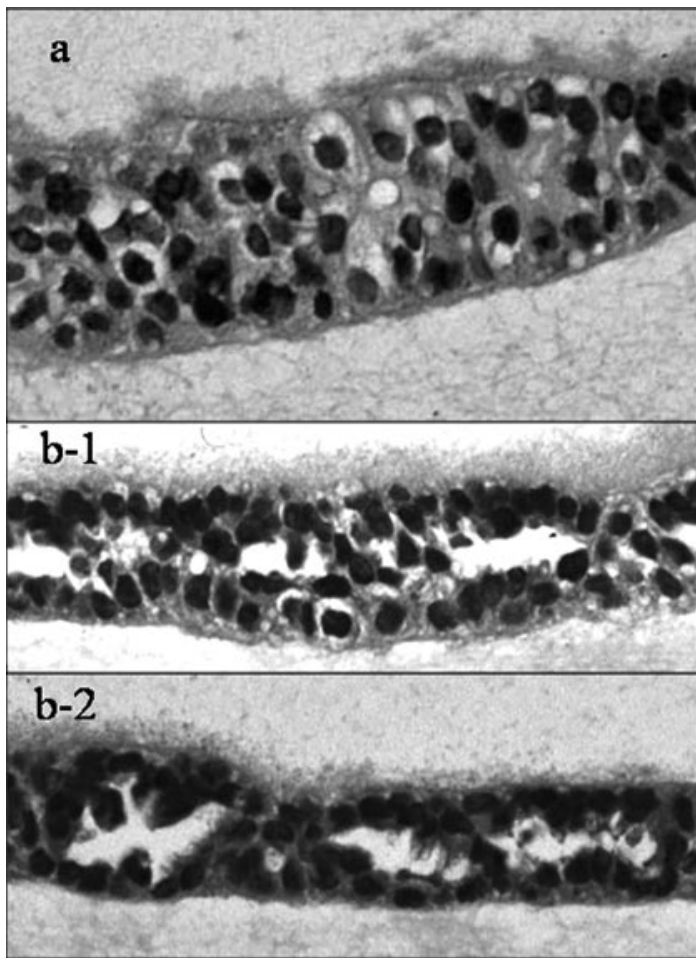

Figure 2. (a) Light microscopy of Ishikawa cells cultured by the floating type I collagen gel method. While some of the cells are slightly polarized, there are no obvious signs of differentiation, such as gland formation, in most parts of the specimen. (b) Light microscopy of SNG-M (2b-1) and HHUA (2b-2) cells cultured by the floating type I collagen gel method. SNG-M and HHUA cells exhibited a columnar shape. Glandular structures were observed. The nuclei of the cells were lined up along the basement membrane, showing obvious polarity.

After culture for $24 \mathrm{~h}$, the medium was removed, the cells were washed three times with phosphate-buffered saline $(\mathrm{pH} 7.2)$ and harvested with a rubber policeman. Then the cells were 


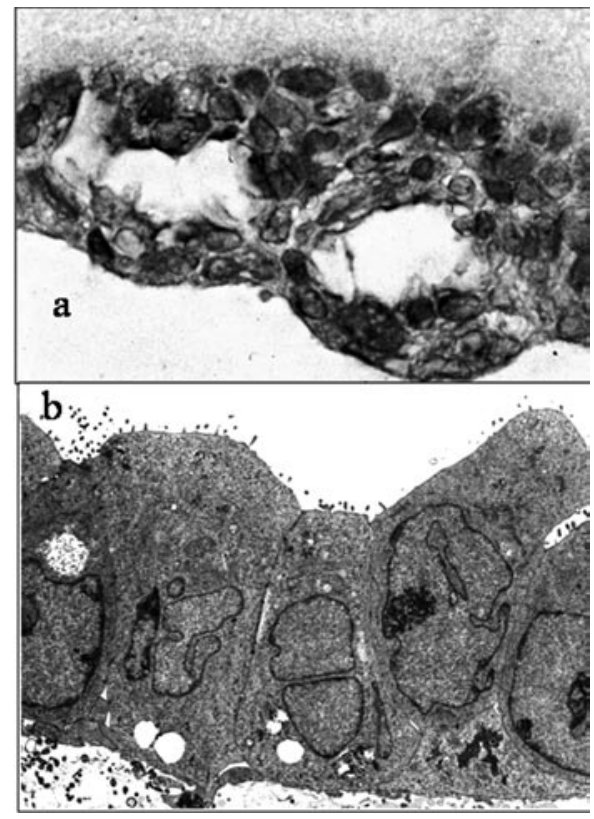

Figure 3. (a) Alcian blue (acid mucopolysaccharide)-stained specimens of the SNG-M cell line cultured by the collagen gel method. Secretion of substances inside the lumens of the glands was also observed. The lumens of the glandular structure were positive for staining. (b) Transmission electron micrograph of HHUA cells cultured by the floating type I collagen gel method.

homogenized and the homogenate was lyophilized. Lipids were extracted from the lyophilized powder with $1 \mathrm{ml}$ of chloroform-methanol $(2: 1$ and $1: 2 \mathrm{vol} / \mathrm{vol})$ for $20 \mathrm{~min}$ at $40^{\circ} \mathrm{C}$. The combined extracts were washed by the Folch method to remove water-soluble radioactive materials and an extract corresponding to $2 \times 10^{6}$ cells was subjected to chromatography on an HPTLC plate $(0.25 \mathrm{~mm}$ thick, Merck, FRG) with chloroform/methanol/acetone/acetic acid/water (8:2:4:2:1 vol/vol). Autoradiograms of the TLC plate were made with X-ray film (X-Omat, Kodak).

\section{Results}

Transplanted tumors in nude mice. Fig. 1 shows H\&E-stained specimens of the tumors formed in nude mice by the transplanted SNG-M (left panel) and HHUA (right panel) cell lines. The primary tumors from which these cell lines were isolated

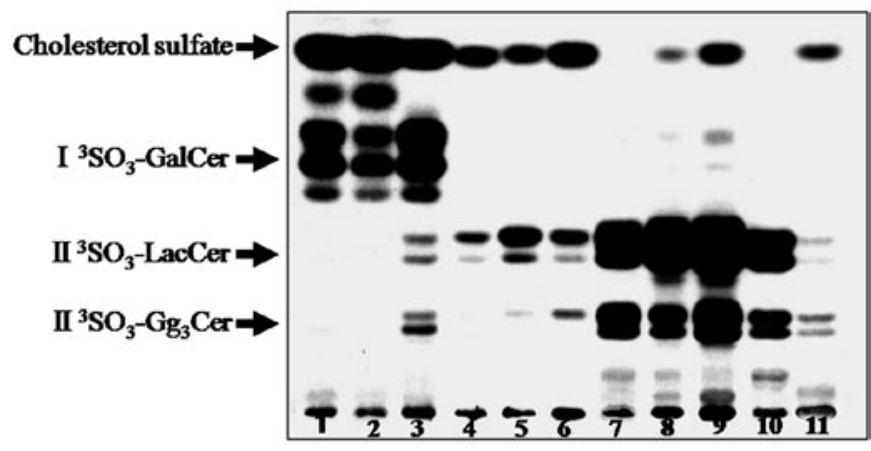

Figure 4. TLC autoradiogram of sulfolipids from $2 \times 10^{6}$ cultured cells of various cell lines derived from endometrial cancer. Four sulfolipids are identified with mobilities on the TLC plate that are identical to those of cholesterol sulfate, $\mathrm{I}^{3} \mathrm{SO}_{3}$-GalCer, $\mathrm{II}^{3} \mathrm{SO}_{3}$ - $\mathrm{LacCer}$ and $\mathrm{II}^{3} \mathrm{SO}_{3}-\mathrm{Gg}_{3} \mathrm{Cer}$.

were moderate to well-differentiated, but the tumors that grew in mice injected with the cells were solid and did not show any gland formation or other signs of differentiation. The cell lines derived from the SNG-II, HEC108 and HOOUA tumors also showed a poorly differentiated morphology.

Floating collagen gel culture. Fig. 2a shows the H\&E-stained specimens of the Ishikawa cell line cultured by the sandwich collagen gel method. While some of the cells are slightly polarized, there are no obvious signs of differentiation, such as gland formation, in most parts of the specimen. Similarly, the SNG-II, HEC108 and HOOUA cell lines cultured by this collagen gel method showed no differentiation. However, in the H\&E-stained specimens of the SNG-M (Fig. 2b-1) and HHUA (Fig. 2b-2) cell lines cultured by the collagen gel method, glandular structures were observed. The cell nuclei were lined up along the basement membrane, showing obvious polarity. Secretion of substances inside the lumens of glands was also observed. Alcian blue (acid mucopolysaccharide)stained specimens of the SNG-M cell line cultured by the collagen gel method are shown in Fig. 3a. The lumens of the glandular structure were positive for staining. Electron microscopy of the HHUA cell line after collagen gel culture (Fig. 3b) showed microvilli protruding into the lumens of the glandular structures and the presence of junctional complexes and desmosomes on the lateral surface.

Table II. Results.

\begin{tabular}{lcccc}
\hline Cell line & $\begin{array}{c}\text { Histological grading } \\
\text { of xenografts }\end{array}$ & $\begin{array}{c}\text { Glandular differentiation by } \\
\text { embedded collagen culture }\end{array}$ & $\begin{array}{c}\text { Cholesterol } \\
\text { sulfate }\end{array}$ & $\begin{array}{c}\text { Sulfoglycolipids } \\
\text { SNG-II }\end{array}$ \\
SNG-M & G3 & - & + & + \\
Ishikawa & G3 & + & + & ++ \\
HEC108 & G3 & - & + & ++ \\
HHUA & G3 & - & - & ++ \\
HOOUA & G3 & + & + & + \\
\hline
\end{tabular}

G1, well-differentiated; G2, moderately differentiated and G3, poorly differentiated adenocarcinoma. 
Sulfolipids in the cell lines. Fig. 4 shows a TLC autoradiogram of the sulfolipids expressed by various cell lines derived from endometrial cancer. The four sulfolipids found on the TLC plate $\left(\mathrm{I}^{3} \mathrm{SO}_{3}\right.$-GalCer, $\mathrm{II}^{3} \mathrm{SO}_{3}$-LacCer and $\left.\mathrm{II}^{3} \mathrm{SO}_{3}-\mathrm{Gg}_{3} \mathrm{Cer}\right)$ were identical to those of cholesterol sulfate. The cell lines were found to express glycolipids containing one of the three sulfate groups ( $\mathrm{I}^{3} \mathrm{SO}_{3}$-GalCer, $\mathrm{II}^{3} \mathrm{SO}_{3}$-LacCer or $\mathrm{II}^{3} \mathrm{SO}_{3}-\mathrm{Gg}_{3} \mathrm{Cer}$ ), while the SNG-M and HHUA cell lines showed no expression of cholesterol sulfate. The results are summarized in Table II.

\section{Discussion}

The extent of differentiation is reported to be an important determinant of the behavior of endometrial cancer. The survival rate of patients with poorly differentiated adenocarcinoma is low as these tumors are often advanced at the time of detection and metastasize easily. However, little is known about the reasons for such tumor behavior.

The present study aimed to elucidate the mechanism of differentiation of endometrial cancer. A culture method was developed to induce differentiation of the cultured cell lines derived from primary tumors. The tumors exhibited gland formation that had become poorly differentiated to anaplastic after a number of passages.

Induction of the differentiation of cultured cells using ECM was previously reported (1). The addition of ECM to cultures causes cells to produce a basement membrane and maintain their original morphology and volume. Subsequently, the cells are cultured under 'physiological' conditions. Matrigel is often used for the induction of differentiation. However, Matrigel contains various biologically active molecules, including ECM, cytokines, proteases and inhibitors, making it difficult to relate a certain effect to a particular agent. Accordingly, using type I collagen, we induced gland formation by a simple culture method. After a monolayer of cells had formed on a sheet of collagen gel, it was allowed to either float freely in the medium or the cells were suspended in collagen and cultured. However, neither method achieved gland formation.

In most of the studies reported thus far, differentiation was induced in cell lines that formed well-differentiated transplanted tumors (1). The present study differs in that we succeeded in inducing the differentiation of adenocarcinoma cell lines which formed poorly differentiated tumors only in mice. This induction was achieved by culture using type I collagen and without any special factors. Furthermore, the cell lines in which differentiation was induced expressed sulfolipids but not cholesterol sulfate (Table II). It has been reported that the induction of differentiation in endometrial cancer using Matrigel can be blocked by anti-laminin antibodies (10), and that laminin binds to sulfolipids to transmit intracellular signals $(11,12)$. This suggests that the induction of differentiation in endometrial cancer cells grown on Matrigel is based on an interaction between sulfolipids and laminin in ECM. The cells used in the present study expressed glycolipids containing one of three sulfate groups: $\mathrm{I}^{3} \mathrm{SO}_{3}$-GalCer, $\mathrm{II}^{3} \mathrm{SO}_{3}$-LacCer or $\mathrm{II}^{3} \mathrm{SO}_{3} \mathrm{Gg}_{3} \mathrm{Cer}$, while differentiation was only induced among cells that did not express cholesterol sulfate. These results lead to the hypothesis that gland formation (differentiation of adenocarcinoma) is induced through an interaction between the type I collagen substrate and cellular glycolipids containing sulfate groups. With an increasing expression of cholesterol sulfate on cell membranes, glycolipids containing sulfate groups would be masked and the interaction with type I collagen would be weakened leading the cells to become poorly differentiated. In previous studies, cholesterol sulfate in keratinocytes has been shown to play a role in the differentiation of squamous epithelial cells through the finding that protein kinase $\mathrm{C}$ is activated by cholesterol sulfate $(13,14)$. Moreover, although differentiation of the squamous and glandular epithelia are two completely different processes, both types of cells are of epithelial origin. Therefore, it is possible that cholesterol sulfate is also involved in the differentiation of glandular epithelium.

Inducing the differentiation of poorly differentiated endometrial cancer in vivo, would result in an improvement in the prognosis of this type of tumor. Thus, based on the results obtained in the present study, we aim to further investigate the induction of differentiation in endometrial cancer cells in vivo and develop differentiation inducers for clinical use.

\section{Acknowledgements}

This work was supported in part by Grants-in-aid for scientific research from the Ministry of Education, Japan (No. 20591962).

\section{References}

1. Hopfer H, Rinehart CA, Kaufman DG and Vollmer G: Basement membrane induced differentiation of $\mathrm{HEC}-1 \mathrm{~B}(\mathrm{~L})$ endometrial adenocarcinoma cells affect both morphology and gene expression. Biochem Cell Biol 74: 165-177, 1996.

2. Kubushiro K, Kojima K, Mikami M, Nozawa S, Iizuka R, Iwamori $\mathrm{M}$ and Nagai $\mathrm{Y}$ : Menstrual cycle-associated alteration of sulfogalactosylceramide in human uterine endometrium. Arch Biochem Biophys 268: 129-136, 1989.

3. Kiguchi K, Takamastu K, Tanaka J, Nozawa S, Iwamori M and Nagai Y: Glycosphingoplipids of various human ovarian tumors: a significantly high expression of $\mathrm{I}^{3} \mathrm{SO}_{3} \mathrm{GalCer}$ and Lewis antigen in mucinous cyst adenocarcinoma. Cancer Res 52: 416-421, 1992.

4. Kubushiro K, Tsukazaki K, Tanaka J, Takamastu K, Kuguchi K, Mikami M, Nozawa S, Nagai Y and Iwamori M: Human uterine endometrial adenocarcinoma: characteristic acquirement of synthetic potentials for $\mathrm{II}^{3} \mathrm{SO}_{3}$-LacCer and Ganglio series sulfoglycosphingolipids after transfer of the cancer cells to culture. Cancer Res 52: 803-809, 1992.

5. Nozawa S, Sakayori M, Ohta K, Iizuka R, Mochizuki H, Soma M, Fujimoto J, Hata J, Iwamori M and Nagai Y: A monoclonal antibody (MSN-1) against a newly established uterine endometrial cancer cell lines (SNG-II) and its application to immunohistochemıstry and flow cytometry. Am J Obstet Gynecol 161: 1079-1086, 1989.

6. Ishiwata I, Nozawa S, Inoue T and Okumura H: Development and characterization of established cell lines from primary and metastatic region of human endometrial adenocarcinoma. Cancer Res 37: 1777-1785, 1977.

7. Nishida M, Kasahara K, Kaneko K, Iwasaki H and Hayashi K: Establishment of a new human endometrial adenocarcinoma cell line, Ishikawa cells, containing estrogen and progesterone receptors. Acta Obstet Gynecol Jpn 37: 1103-1111, 1985.

8. Morizawa T: Establishment and characterization of a endometrial cancer cell line. J Jpn Soc Clin Cytol 26: 433-442, 1987.

9. Shimizu H, Inoue M and Tanizawa O: Adoptive cellular immunotherapy to the endometrial cancer cell line xenografts in nude mice. Gynecol Oncol 34: 195-199, 1989.

10. Behrens P, Meissner C, Hopfer H, Schümann J, Tan MI, Ellerbrake N, Strunck E and Vollmer G: Laminin mediates basement membrane induced differrentiation of HEC 1B endometrial adenocarcinoma cells. Biochem Cell Biol 74: 875-886, 1996. 
11. Taraboletti G, Rao CN, Krutzsch HC, Liotta LA and Roberts DD: Sulfatide-binding domain of the laminin A chain. J Biol Chem 265: 12253-12258, 1990.

12. Kawakita M, Tsuji Y, Nakata Y, Ogasawara T, Takemura T, Isojima $\mathrm{S}$ and Koyama K: Progesterone treatment decreases sulfate carbohydrate antigen on endometrial carcinoma cells an inhibits the cell binding to laminin. Gynecol Oncol 57: 313-320, 1995.
13. Kuroki T, Ikuta T, Kashiwagi M, Kawabe S, Ohba M, Huh N, Mizuno K, Ohno S, Yamada E and Chida K: Cholesterol sulfate, an activator of protein kinase $\mathrm{C}$ mediating squamous cell differentiation: a review. Mutat Res 462: 189-195, 2000.

14. Kashiwagi M, Ohba M, Chida K and Kuroki T: Protein kinase C eta (PKC eta): its involvement in keratinocyte differentiation. J Biochem 132: 853-857, 2002. 